\title{
Percepción social y estética del espacio público urbano en la sociedad contemporánea
}

\section{Social and Aesthetic Perception of Urban Public Space in Contemporary Society}

\author{
Sergio García-Doménech \\ Escuela Politécnica Superior. Departamento de Edificación y Urbanismo. Universidad de \\ Alicante \\ sergio.garcia@ua.es
}

Recibido: 9 de abril de 2013

Aprobado: 18 de junio de 2013

\section{Resumen}

El espacio público urbano se encuentra actualmente en un periodo de crisis, pero pugna por seguir representando un importante papel, para la sociedad en general y para la ciudadanía en particular. Ese papel, formado a través de múltiples componentes culturales, requiere de una dimensión tanto social como estética para entrar, por derecho propio, en el acervo ciudadano y en el patrimonio urbano. Este artículo analiza las circunstancias de esa crisis desde tres enfoques: el conceptual, el social y el estético. Respecto de éste último, se realiza una revisión de las principales corrientes estéticas que, a lo largo de la segunda mitad del siglo XX, han tenido influencia sobre la actual definición del espacio público. A partir de ese triple análisis crítico, se exponen los principales resultados acerca de la percepción actual - social y estética - que la ciudadanía contemporánea tiene sobre el espacio público. El estudio concluye con la necesidad de poner en valor la dimensión estética para potenciar la social y viceversa. Para ello se proponen tres variables que informan esa relación: la planificación urbana, la arquitectura y el diseño del espacio público.

Palabras clave: espacio público, estética urbana, sociedad urbana, sentido de lugar, percepción ciudadana.

García-Domenech, S. (2014): Percepción social y estética del espacio público urbano en la sociedad contemporánea. Arte, individuo y Sociedad, 26 (2) 301-316.

\begin{abstract}
The urban public space is currently in a critical period. But it struggles to continue representing an important role for general society, and particularly citizenship. That role, formed through multiple cultural approaches, requires a social and aesthetic dimension to enter in urban heritage. This article examines the circumstances of the crisis since three approaches: conceptual, social and aesthetic. Regarding the last one, a previous review is made concerning the principal aesthetic tendencies of the second half of the twentieth century. Starting from this triple approach, the main results about public space and contemporary citizenship perception — social and aesthetic — are presented. The study concludes with the need of highlight the value of the aesthetic dimension to boost social and vice versa. In order to inform the relation, three variables are suggested: urban planning, architecture and design of public space.
\end{abstract}

Keywords: public space, urban aesthetic, citizenship, sense of place, citizenship perception. 
García-Domenech, S. (2014): Social and Aesthetic Perception of Urban Public Space in Contemporary Society. Arte, individuo y Sociedad, 26 (2) 301-316.

Sumario: 1. La crisis conceptual del espacio público, 2. La crisis social del espacio público, 3 . Aproximación a las principales corrientes estéticas del diseño urbano surgidas en la segunda mitad del siglo XX, 4. La crisis estética del espacio público, 5. La percepción ciudadana contemporánea del espacio público, 6. Conclusiones. Referencias

Este artículo recoge resultados de la investigación "El espacio público urbano de la ciudad de Alicante desde la Transición Política (1975-1995). Evolución, transformación y reinterpretación" financiada por el Instituto Alicantino de Cultura Juan Gil-Albert (Excma. Diputación Provincial de Alicante), obtenida en concurrencia competitiva.

\section{La crisis conceptual del espacio público}

La sociedad actual parece tener una percepción confusa sobre el espacio público urbano, confusión que parte de su propio concepto. Zona verde, plaza o jardín son términos que la ciudadanía tiende a confundir y que pueden englobarse bajo el común denominador conceptual de espacio público. Zona verde es un concepto positivista y funcional de la ciencia urbanística con origen en el urbanismo del siglo XIX y desarrollo racionalista a partir del XX. Responde a criterios más cuantitativos -estándar por habitante- que cualitativos de necesidad ciudadana. Pero la mera previsión que la planificación urbana hace de estos espacios no le otorga la condición de plaza urbana, ni mucho menos la de jardín.

Por otra parte, un debate recurrente en las ciudades es el dilema entre plaza o jardín. En las ciudades de tradición mediterránea ha habido tradición de ambos, pero conviviendo siempre por separado. La sociedad contemporánea ha tendido a mezclarlos bajo el común denominador de espacio público. La plaza, con raíces en el ágora de la cultura clásica y posterior desarrollo medieval, es abierta, dura, casi vacía, desprovista de vegetación y pensada para albergar todo tipo de actividades urbanas colectivas (Favole, 1995). El jardín, alcanza raíces bíblicas —el Edén- y mantiene su concepción privada hasta el siglo XIX. El jardín es originalmente cerrado y delimitado, blando, provisto de vegetación, ornamentado con esculturas y pensado para dar placer a los sentidos (Assunto, 1991; Von Buttlar, 1993; Ruiz Gómez, 2012). La evocación, el misterio y la idea de lo sublime, inherentes al pensamiento romántico, serían valores omnipresentes en la conformación estética de estos espacios. En los jardines, el elemento verde en general y el árbol en particular, además de cumplir características funcionales, como sombra, humedad o abrigo del viento (Martínez Sarandeses, 2001) o ambientales, como paisaje, color o acústica (Bailly, 1979) posee también implicaciones más profundas, representativas o significantes, como presencia, identidad o historia: "los árboles tienen un significado muy hondo y crucial para los seres humanos. La significación de los viejos árboles es arquetípica; en nuestros sueños representan muy a menudo la totalidad de la personalidad" (Alexander, Ishikawa \& Silverstein, 1980, p. 701).

La apertura a la ciudad de algunos jardines privados, sobre todo a partir de las transformaciones urbanas postindustriales del siglo XIX —-derribos de murallas, re- 
formas urbanas y desarrollo de los ensanches-, la creación de otros nuevos y el ajardinamiento de algunas plazas medievales, configuraría un buen número de jardines urbanos en muchas ciudades. Algunos de estos jardines se han ido conformando históricamente como lugares urbanos de calidad, lo que ha llegado a otorgarles una percepción social de plaza urbana como lugar de interacción ciudadana, independientemente de sus características formales y estéticas. Por ello, en algunas intervenciones actuales realizadas sobre trazados ajardinados románticos del XIX, se ha intentado recuperar el espacio como plaza urbana (Fig. 1A, 1B).
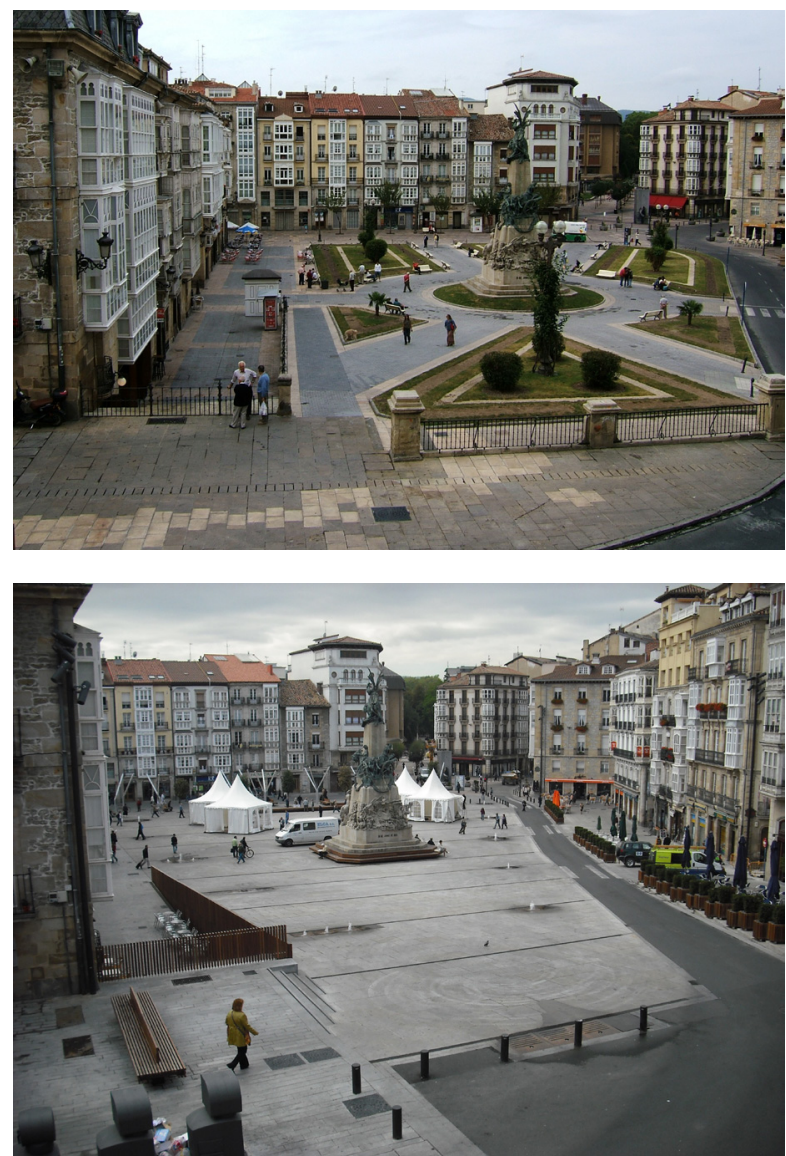

Figura 1A y 1B. Plaza de la Virgen Blanca, Vitoria. Aspecto en 2006 y en 2008. Fuente: elaboración propia

\section{La crisis social del espacio público}

Dos de los resultados que - al menos en términos sociales - ha dejado el pensamiento posmoderno de las últimas décadas del siglo XX, son el individualismo y la pasión por la privacidad (Jameson, 1995; Lyotard, 1999; Amendola, 2000; Verdú, 2001; Popelka, 2009; Sequera \& Janoschka, 2012). Desde comienzos de los años ochenta 
del pasado siglo, ha aparecido una consecuencia urbana directa de ello: la proliferación por toda Europa de modelos urbanos residenciales, por lo común importados de la cultura norteamericana, basados en la preferencia de la propiedad privada sobre el espacio público (Rogers \& Gumuchdjian, 2000). Estos modelos se caracterizan por el aislamiento del individuo frente a la sociedad, promoviendo viviendas unifamiliares aisladas, donde la base de la propiedad privada es la norma: los espacios públicos quedan relegados a la simple vialidad, con la única función de la movilidad rodada, que además es igualmente privada. La tradición europea de ciudad compacta — sobre todo en la Europa Mediterránea-, basada en el protagonismo del espacio público y de la vida colectiva, se ha visto radicalmente desplazada por estos modelos de ciudad. De esta manera, el espacio público urbano entraría en una crisis funcional y de identidad cuya culminación desembocaría en la aparición y posterior proliferación de los paradójicos "espacios públicos privatizados" (Amendola, 2000; Borja, 2003; Borja \& Muxí, 2003; Németh, 2012) en forma de grandes complejos comerciales y de ocio.

Estos lugares no dejan de poner de manifiesto unas radicales diferencias con los verdaderos espacios públicos: los verdaderos son socialmente integradores, pero los privatizados son excluyentes; los verdaderos generan ciudad, incluso son la ciudad en sí misma (Borja, 2003), los privatizados la segregan y desintegran; los verdaderos están pensados para el ciudadano, los privatizados están pensados para el cliente; los verdaderos tienen identidad propia, los privatizados son neutros y abstractos desde el principio, carecen de personalidad urbana, arquitectónica y estética; los verdaderos son, en el contexto urbano, económicos, los otros son antieconómicos, multiplican las movilidades urbanas de forma tan espectacular como forzada y siempre van por delante de las infraestructuras viarias necesarias para absorber sus flujos; en los reales puede desarrollarse cualquier actividad urbana, aparecer la sorpresa e incluso la inseguridad y el descontrol, en los privatizados sólo están previstas las actividades reguladas para las que fueron expresamente concebidos, las únicas sorpresas están diseñadas con fines de consumo y por supuesto, todo es tan seguro como controlado.

La complejidad de las variables urbanas, sociales, políticas, económicas y culturales que convergen en este fenómeno, ha desembocado en una profunda crisis social del verdadero espacio público de finales del siglo XX. El abandono comercial de la ciudad tradicional ha mermado el uso del espacio público y rompe la continuidad e interacción de los usos urbanos deseables en toda ciudad. Esto redunda en un paralelo abandono de la potencial dimensión artística del mismo, relegada a un simple cumplimiento funcional ajeno a toda emoción estética. En algunos casos, se ha llegado al absurdo urbano: creación de nuevos espacios públicos que quedan desiertos al uso y degradación paulatina de los espacios históricos. Todo ello, en pro de los citados modelos residenciales importados que limitan las actividades colectivas a las meramente comerciales o de ocio, concentrándolas en enormes contenedores cerrados tan impersonales como ajenos a la formación de ciudad.

Pero los errores de diseño también han contribuido a la crisis social del espacio público. Por ejemplo, un error recurrente ha sido la tendencia a zonificar el espacio para albergar actividades concretas y especializadas. Esto no ha dejado de representar una intención de racionalizar el uso del espacio público a través del diseño como si se tratara de un espacio privado. Pero la complejidad de la experiencia urbana, en 
cuanto que se compone de un usuario abstracto, tan complejo y cambiante como es el ciudadano, se presta a mutación permanente (Norberg-Schulz, 1975). El espacio público es el lugar de encuentro ciudadano por excelencia, pero también es el foro con mayor índice de publicidad de toda la ciudad, el lugar donde más interacciones ciudadanas se pueden celebrar, donde se circula y se está para actos y actividades de lo más variopinto, donde se protesta y donde se festeja, donde se ve y se es visto, donde se exhibe una identidad personal o grupal, pero también paradójicamente, donde se puede disolver la persona en el anonimato urbano:

La vieja civitas tradicional cobró sentido histórico al materializar los comportamientos propios de unas sociedades, proclives a la vida pública, que se manifestaban con abundancia de celebraciones y ritos que por su condición popular habrían de reflejarse en la forma de la ciudad (De Gracia, 1992, p. 27).

La capacidad de albergar usos alternativos a los inicialmente diseñados por la zonificación en los espacios públicos ha puesto en crisis ese principio racional, de manera que la versatilidad y flexibilidad en la zonificación se ha perfilado cada vez más como un índice de calidad en el diseño del espacio público urbano contemporáneo.

\section{Aproximación a las principales corrientes estéticas del diseño urbano surgidas en la segunda mitad del siglo $X X$}

La llegada del Movimiento Moderno en las primeras décadas del siglo XX, plantea entre sus ideales estéticos el abandono de la historia (Montaner, 1993) y a la par, un cierto abandono de lo público, que es sustituido por lo funcional o, en el mejor de los casos, por lo colectivo. El urbanismo moderno, obsesionado por la zonificación y sumido en el vértigo de la velocidad y el progreso, se había olvidado de la historia y por extensión, de la ciudad histórica. Esta ciudad histórica nos había legado un testamento urbano escrito a través del espacio público, verdadero germen generador de ciudad. Pero para la modernidad, las plazas públicas de los centros urbanos, lugares que identifican la estética de la ciudad, se percibían como obsoletas.

Varias de las posteriores corrientes críticas de la modernidad — sobre todo a partir de finales de los años cincuenta del siglo XX- basarían su estrategia en la recuperación del espacio público como elemento generador de la ciudad. Desde entonces, las principales corrientes revisionistas y críticas con los postulados de la modernidad arquitectónica intentarían permanentemente una búsqueda de nuevos lenguajes urbanos a lo largo de la segunda mitad del siglo. En el caso concreto de la plaza pública urbana, el interés por encontrar ese lenguaje estético, había llegado a superar el interés por el uso y la función de la propia plaza (Favole, 1995, p. 12). En ese sentido, Favole realiza una interpretación más estética que social del espacio público. Desde ese enfoque, podemos resumir en cuatro las corrientes estéticas más importantes que han tenido influencia sobre el diseño del espacio urbano: el Contextualismo de los años cincuenta, el Townscape de los sesenta, la Tendenza italiana de los setenta y la corriente Postmoderna de los ochenta.

El Contextualismo, formulado y estudiado por J.M. Montaner (1993) se entronca en la continuidad de la arquitectura del Movimiento Moderno, pero matizando el ca- 
mino puro de su ideario estético en el marco de las tradiciones locales (Moix, 1994, p. 24). El giro crítico sobre la radicalidad positivista de la Carta de Atenas junto con la reacción de la corriente crítica fenomenológica encabezada por Walter Benjamin (Sæter, 2011), encuentra eco en la humanización de la arquitectura moderna, que contextualiza el formulario moderno, en parte gracias al auge de las ciencias sociales durante las décadas de los cincuenta y sesenta: "En este sentido, la revalorización de la esfera de la vida cotidiana y de la psicología compleja de los usuarios va tomando un papel predominante en las ideas de los arquitectos" (Montaner, 1993, p. 27).

Casi paralelamente al Contextualismo, pero de manera independiente, sería desarrollada otra corriente estética urbana, que se enmarca en la tradición paisajística propia de la cultura anglosajona: el townscape o paisaje urbano (Cullen, 1974), en analogía al landscape o paisaje territorial. Esta corriente revisa los postulados de Camillo Sitte (1980 [1889]) formulados a finales del siglo XIX, retomando criterios de paisaje urbano y recuperando la visión artística de la ciudad. La influencia de Sitte llegaría también a influir otros teóricos y movimientos posteriores como Christopher Alexander (1980), el Movimiento Situacionista (Andreotti \& Costa, 1996) o el Morfologismo (Aymonino, 1981).

La Tendenza italiana de los años setenta encuentra en Aldo Rossi (1977) a su principal teórico. La reflexión de esta corriente sobre la ciudad y sus espacios públicos, retoma un estatismo clásico fuertemente relacionado con el surrealismo pictórico de las piazze del pintor G. De Chirico: "la seducción de las plazas del italiano ha desbordado este género pictórico para invadir el ámbito propio del proyecto arquitectónico" (Marchán Fiz, 1986, p. 118). Pero la pronta crisis de este movimiento partiría de su vuelta atrás respecto de la pretendida modernidad: "se volvía a la visión estática y al deseo de monumentalidad, solidez y permanencia de la arquitectura académica y se eludía la concepción más efímera y ligera de la arquitectura propuesta por el Movimiento Moderno" (Montaner, 1993, pp. 140-141).

En torno a la Posmodernidad, se han desarrollado enfoques desde diversas disciplinas (Popelka, 2009). Por lo tanto, no conviene utilizar este término sin un adecuado contexto cultural. J.M. Montaner (1993), coherente con la complejidad del término "arquitectura posmoderna" lo interpreta como aquella que "sirve para designar ciertas tendencias de la arquitectura que son más marcadamente historicistas, hedonistas, eclécticas o densas en citaciones" (p. 178). Esta arquitectura neoecléctica, encajaría perfectamente dentro de la cultura posmoderna "no selectiva, masiva y popular" (Verdú, 2001, p. 95). Pero lo haría en un plano diferente, eminentemente estético, sin profundizar en su vertiente epistemológica (Jameson, 1995; Lyotard, 1999), antropológica (Augé, 1993), sociológica (Amendola, 2000), político-económica (Turner, 2002) o incluso disciplinar (Koolhaas, 1996).

\section{La crisis estética del espacio público}

La crisis estética actual del espacio público se pone en evidencia cuando observamos las intervenciones y actuaciones urbanas más anodinas. En ellas, aparecen recurrentemente ciertas constantes que la demuestran, como la nostalgia, el horror vacui, la incomprensión social de la abstracción, la falta de diálogo entre arte urbano y espacio 
público o el fetichismo urbano. La nostalgia es un sentimiento que destruye toda defensa del concepto de modernidad aplicada al arte en general, y a la estética urbana en particular (Miranda, 1999). En la visión más pública de esa estética urbana -fachadas arquitectónicas y diseño de espacios públicos-, con frecuencia se ha dejado de lado la esencia histórica y la vertiente cultural de cada lugar, a favor de un imaginario colectivo, generalmente trivial y carente de justificación. Esta nostalgia ha sido a la vez causa y efecto del deseo - que no de la necesidad - de la ciudadanía (Amendola, 2000). Es una parte más de la influyente mediatización sobre la cultura popular: "las estrategias comerciales basadas en la nostalgia y la recuperación del pasado junto a la arquitectura hecha de citas y de revivals tienden a anular en la escena urbana la distinción entre ayer y hoy, entre presente y pasado" (Amendola, 2000, p. 180). Durante las últimas décadas del siglo XX se ha prodigado el empleo de lenguajes anacrónicos de fácil reconocimiento popular. Esas actuaciones han acabado dando el tono general a la imagen del espacio público de las ciudades con unos resultados que por lo general han demostrado una importante carencia de cultura urbana, falseando la memoria colectiva. La nostalgia, las modas o la estética de citas, ha afectado de lleno al diseño urbano del espacio público. El "facilismo" (Miranda, 1999) del recurso a las estéticas historicistas basadas en la recuperación de maneras y formas del pasado, se ha prodigado considerablemente en todas las ciudades de nuestro entorno cultural.

Otro de los principales síntomas de la crisis estética del espacio público contemporáneo, ha sido el horror vacui, el miedo al vacío. Bachelard (1994) analiza este sentimiento como la "hipertrofia del sueño de habitar todos los objetos huecos del mundo" (p. 158). La inexistente tradición de oficio en el proyecto moderno del espacio público urbano, con escaso dominio de las herramientas, tanto en sentido material - pavimentos, tratamiento de rasantes, mobiliario, etc. - como fenomenológico - luz, acústica, soleamiento, confort-, se ha visto potenciada por la radical barrera existente entre el espacio público y la arquitectura que lo rodea y conforma. Esta circunstancia ha potenciado un cierto protagonismo forzado del diseño del primero llenándolo con objetos diversos, como intentando dar contenido a un espacio que por concepto, como espacio libre, no lo necesita. La crisis estética de algunos espacios públicos se ha querido paliar por un despliegue de objetos y contenidos materiales, que sólo han conseguido efectos perturbadores para la correcta percepción espacial por parte del usuario.

En pleno siglo XXI, la incomprensión de la abstracción aún sigue siendo una realidad en la sociedad ante toda experiencia estética, incluyendo la urbana. El contraste de un espacio público abstracto frente a un entorno figurativo, produce un efecto de sorpresa en la sociedad, inherente a toda obra artística de vanguardia (Arnau, 2000, pp. 182-184). El despliegue figurativo habitual del marco arquitectónico en los espacios públicos históricos, se presta especialmente al empleo de la geometría como mecanismo formal de abstracción:

La adopción de materiales artificiales, en ocasiones altamente tecnificados, con pérdida de cuerpo matérico, en favor de formas desprovistas de cuantos atributos distraigan su mera definición como realidades esencialmente geométricas, favorece la idea de abstracción. Por esa vía se promueve la confrontación formal, 
dado que dichos materiales son empleados para introducir volúmenes elementales en medio de la riqueza figurativa de los cascos históricos cumpliendo un papel nada silente (De Gracia, 1992, p. 119).

Otra circunstancia que evidencia la crisis estética del espacio público es la falta de diálogo entre arte urbano - esculturas, monumentos y otros elementos artísticos- y el propio espacio en el que se implantan. El arte público urbano, a diferencia de otras expresiones artísticas, suele concebirse para que esté situado en un lugar concreto, y sólo en él. Esa relación continente-contenido es inherente al intrínseco valor estético de la obra de arte: "lo singular en una ciudad no son sus monumentos, sino la disposición de ellos en su entorno [...]. El hecho escultórico o arquitectónico refleja la convicción de lo óptimo de un asentamiento, que lo dispone, lo sella y lo simboliza" (Ayús, 1996, p. 65). La ubicación no puede ser universal cuando la relación entre objeto y espacio es muy estrecha y solidaria, algo que se puede reconocer ejemplarmente en El Peine del Viento de Chillida y la actuación urbana de Peña Ganchegui (Fig. 2).

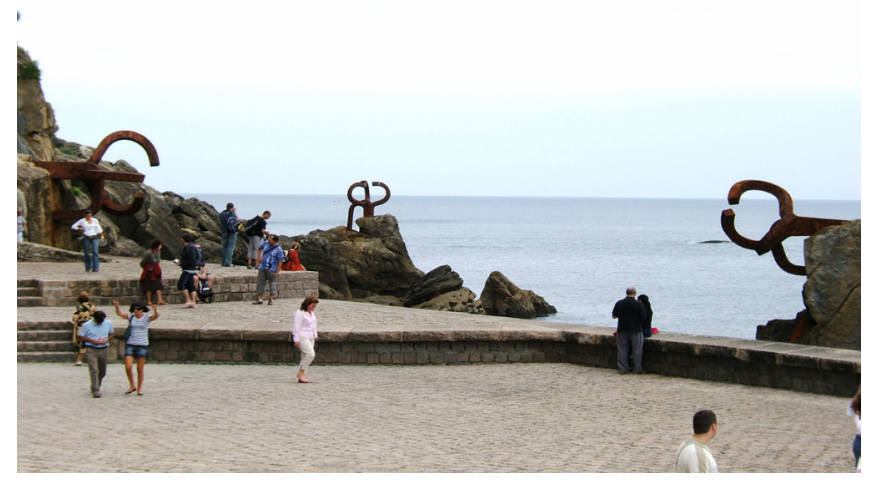

Figura 2. E. Chillida y L. Peña Ganchegui, Peine del Viento y Plaza del Tenis en San Sebastián, 1977. Fuente: elaboración propia (2006)

Pero cuando se altera esa relación entre objeto y entorno, se pierde toda la sustancia creativa, aparecen problemas de escala y proporción, de observación estática o dinámica y de accesibilidad a la obra de arte, que no hacen otra cosa que alterar su razón de ser, su mensaje estético y su verdad: aparece el absurdo urbano. Augé (1993) advierte que "el monumento, como lo indica la etimología latina de la palabra, se considera la expresión tangible de la permanencia o, por lo menos, de la duración" (p. 65).Una prueba de ello son algunas fuentes ornamentales de las plazas públicas, que han pasado de ser auténticos hitos que identifican y cualifican el espacio en el que se implantan a utilizarse como un objeto más para llenar indiscriminadamente el espacio 
urbano usando modelos estandarizados, despersonalizados, de catálogo, realizados sin objetivo concreto y ubicados con total indiferencia respecto al entorno urbano.

Finalmente y en relación a esta cuestión, también aparece en la ciudad contemporánea el fenómeno del fetiche urbano - entendido como objeto de culto, veneración o atracción para una determinada persona o colectividad- que también encuentra su correspondencia en la estética urbana (Kaika \& Swyngedouw, 2000). El fetiche urbano aparece, por ejemplo, cuando se reimplantan objetos con funciones obsoletas - como antiguos quioscos o fuentes sin uso - fuera de la evolución lógica del lugar, y que por lo tanto quedan reducidos a meros objetos de culto; aún es peor cuando el objeto de culto es de nueva planta - falso- e imita el histórico. En ese caso, se rompe además la autenticidad, la virtud intrínseca de aquello que tiene carácter sin necesidad de justificarlo. Auténtico es lo que constituye un ente por sí mismo - autoéntico-y tiene, entre otras consecuencias, el reconocimiento universal del carácter emanado de esa autenticidad. También la originalidad deviene como efecto directo de la autenticidad. Todo lo auténtico es, por ende, original. Pero cuando se busca la originalidad como mero efecto al margen de la autenticidad, todo suele acabar en un despropósito, en un dislate. En ese sentido, la falsación, esto es, la aplicación científica de pruebas de autenticidad a un determinado hecho para poner en crisis su presunta veracidad (Popper, 1982 [1934]), resulta altamente satisfactoria cuando se aplica sobre las intervenciones urbanas presuntamente falsas (Miranda, 1999, pp. 34-46).

\section{La percepción ciudadana contemporánea del espacio público}

El mundo que nos rodea no siempre es el que aparentemente es, sino el que somos capaces de percibir a través de los sentidos y, lo que es más importante, el que filtramos a través de nuestro contexto cultural y de nuestra propia memoria. La percepción humana del espacio urbano contribuye a crear el lugar, el topos aristotélico. La percepción no es algo universal. La base cultural y la experiencia anterior aportan diversidad a la percepción de las cosas y hace que la misma se convierta en un acontecimiento sensorial racional a la par que personal (Bailly, 1979, p. 20-24).

Por ejemplo, la percepción del tamaño de los elementos urbanos, puede depender enormemente del entorno y de la posición o relación con el medio en el que se ubican. Por eso, algunos magníficos ejemplares de arbolado pueden percibirse diferentemente en función del tamaño del espacio público en el que se implantan. En contextos urbanos más reducidos, la proximidad del entorno edificado potencia dicho efecto perceptivo. La visión de muchas iglesias y catedrales históricas, a pesar de que hoy en día no puedan considerarse los edificios más grandes en una ciudad contemporánea, cuando las vemos en la estrechez de un tejido urbano medieval, mantienen el impacto perceptivo que recibe el espectador urbano. La luz también juega un importante papel en la percepción urbana. Las diferentes presencias de arbolado motivan la peculiar percepción que tenemos de ellos, sin menoscabar precisamente el carácter que uno y otro reciben a través de esta diferencia.

No obstante todo lo anterior, una de las principales cualidades que provocan un cambio perceptivo del espacio público no es estética, sino social: el espacio público, para que esté vivo, requiere de uso ciudadano, cuanto más intenso, mejor (Borja \& 
Muxí, 2003). Las diferencias perceptivas entre un espacio socialmente activo y otro vacío son radicales. En los espacios públicos vacíos aumenta la percepción del tamaño y la distancia, mientras que en los que están fuertemente densificados aparentan reducirse y acortarse (Fig. 3A, 3B).
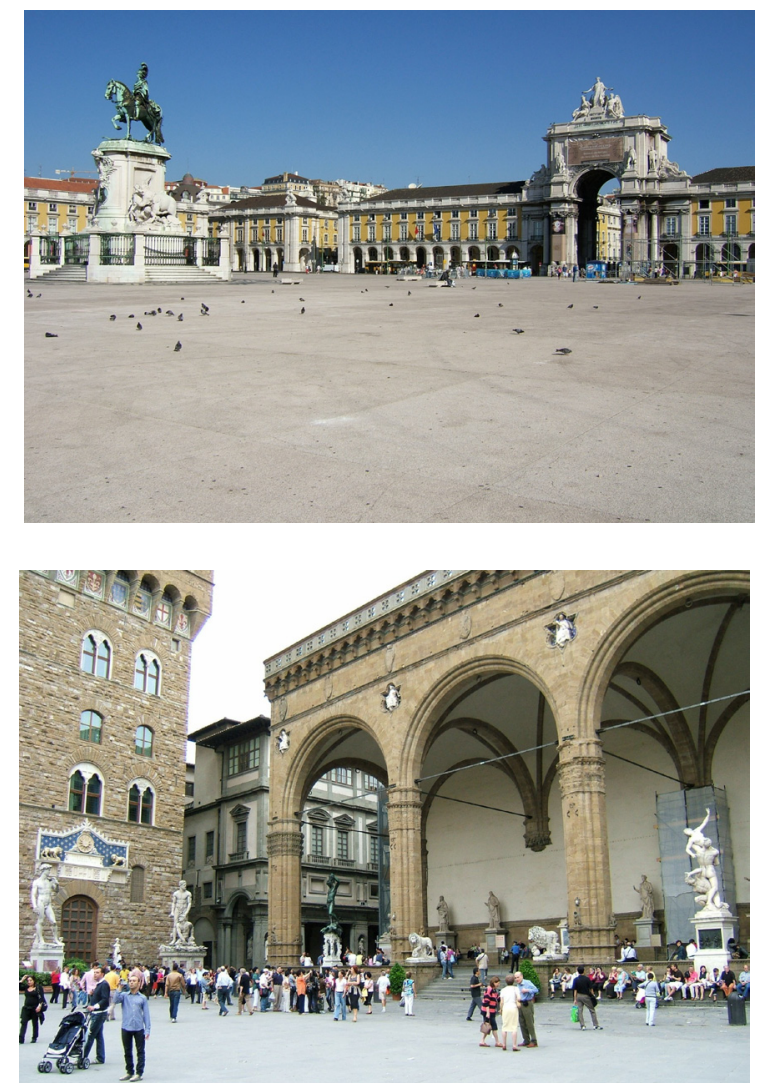

Figura 3A, 3B, Praça do Comércio, Lisboa y Piazza della Signoria, Florencia. Fuente: elaboración propia (2007 y 2008)

También la posición relativa del perceptor puede llegar a intercambiar esta sensación: la visión de un espacio público lleno de gente desde una posición alta da una apariencia de mayor tamaño respecto a cuando está vacío. Ello se debe no sólo por su observación, sino por la entrada en juego de otros sentidos, como el oído, ya que el rumor de la gente o de sus pisadas, contribuyen a magnificar la percepción general de un espacio público densificado (Fig 4A, 4B). 

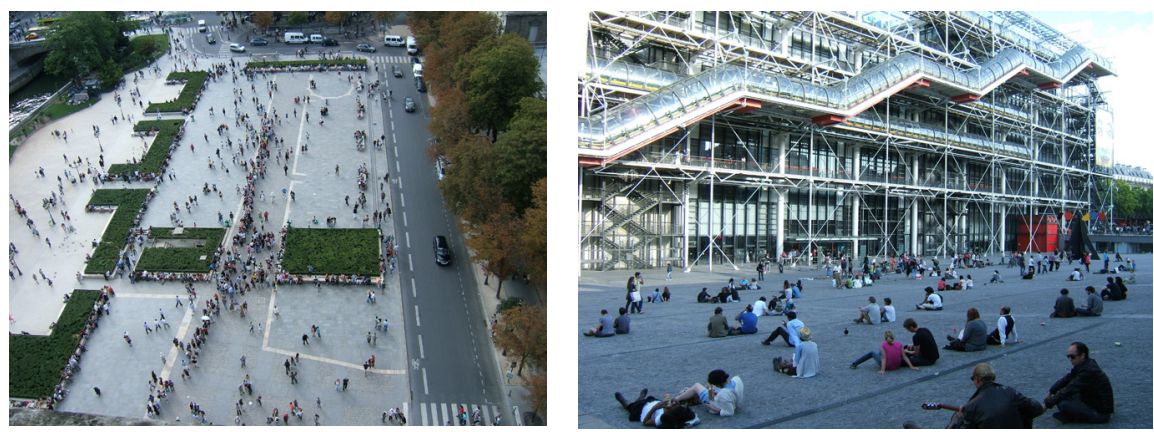

Figura 4A, 4B. Explanada de Notre-Dame desde las torres de la catedral y Place Georges Pompidou, París. Fuente: elaboración propia (2011)

La experiencia de la percepción es individual y personal, pero la intervención del factor sociocultural -eminentemente antropológico- da un enfoque perceptivo más avanzado del espacio colectivo: el espacio existencial (Norberg-Schulz, 1975). La percepción de las interacciones humanas en una ciudad —más que de la ciudad como puro artificio material- es la experiencia personal que mejor justifica la identidad y carácter de un ente urbano.

Todo entorno urbano presenta un paisaje, un territorio visible por un observador desde una determinada posición y que intentamos percibir desde una óptica estética (Ruiz Gómez, 2012, p. 148). Por ello podemos afirmar la existencia —o la necesidad - de un paisaje urbano. La ciudad, en el fondo, no deja de ser un escenario - lugar donde se representan escenas- en el que los actores - ciudadanos- representan la función urbana cotidianamente. El decorado es el espacio público y el fondo de escena de ese decorado, la arquitectura (Arnau, 2000, pp. 64-66).

En muchos espacios públicos de urbanización originalmente decimonónica o de principios del siglo XX, el centro del espacio público aparece señalado con un hito visual, simbólico o funcional. Con los debates finiseculares sobre estética urbana anteriormente expuestos, el centro del espacio público deja de ser el obligado foco de atracción visual y tiende a liberarse. Muchas de estas discusiones habían tomado como modelo los trabajos teóricos sobre estética urbana de Camillo Sitte. Defensor de la idea de concebir la ciudad desde la mirada sensible de un artista y, mediante el estudio de la ciudad histórica, Sitte había abogado por evitar la presencia de elementos urbanos en el centro de las plazas, desde una perspectiva estética pero a la vez funcional (1980 [1889], p. 27-40). La posterior reinterpretación y adaptación contemporánea de esa teoría urbana combinaría la percepción estética con la social: a la vez que mantenía la idea de liberar el centro de las plazas, optaría por potenciar los bordes de las mismas con entornos que resultaran a la par, activos y atractivos. En efecto, la acumulación de elementos de interés, actividades y focos de atracción en los bordes de una plaza, genera una deliberada tensión entre los mismos que determina la vivacidad de uso del espacio público. Una plaza con mucha atracción y actividad en su perímetro y con su centro liberado es una plaza sumamente viva: las interconexiones e interrelaciones entre estos bordes producen que toda la zona central 
del espacio público sea un hervidero de actividad, una vorágine urbana donde tienen cabida todo tipo de usuarios y de actividades heterogéneas. Para garantizar esa tensión urbana, resulta muy recomendable que tanto las actividades de atracción en los bordes participen del espacio público como que el propio espacio público participe de las actividades de atracción: son los espacios de transición entre lo estrictamente público - espacio central de la plaza - y lo estrictamente privado - arquitecturas perimetrales-. Esta idea de fortalecer los bordes del espacio público y liberar los espacios centrales, justifica la buena acogida histórica y vigencia contemporánea - tanto social como estética- de los espacios porticados habituales en las plazas mayores, limitados por soportales que generan a través de la propia arquitectura ese espacio de transición anteriormente aludido y enriquecen importantemente la relación entre espacio público y espacio privado (Fig. 5).

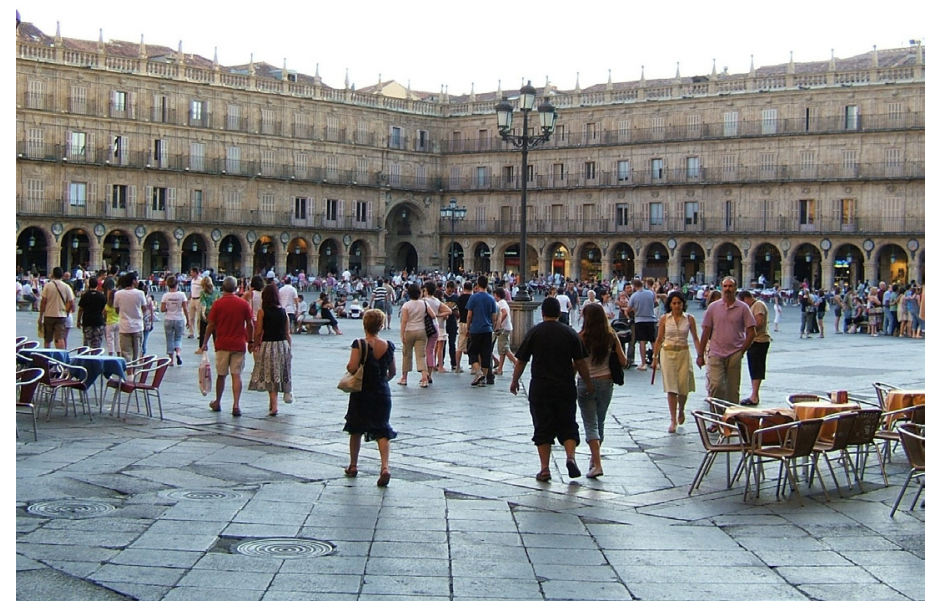

Figura 5. Plaza Mayor, Salamanca. Fuente: elaboración propia (2008)

Otro factor, frecuentemente ignorado o minusvalorado, que relaciona interesantemente ambas percepciones del espacio público urbano - la social y la estética- es el fenómeno sonoro. La preocupación por la calidad sonora de nuestras ciudades no ha parado de aumentar en los últimos tiempos, identificando el ruido como uno de los defectos de la vida urbana contemporánea. Existe un enfoque del ruido en las ciudades, que es el de su percepción social o más en concreto, sociocultural. Vivimos en —y somos - una sociedad urbana ruidosa (Zárate, 1991, pp. 235-237). Pero también puede hablarse de sonidos urbanos sin connotaciones negativas. Los espacios públicos tienen sus sonidos característicos, no necesariamente perturbadores ni desagradables. Es más, pueden fortalecer y contribuir a enriquecer el sentimiento de lugar que, en esencia, debería acompañar a todo espacio público: el tañido de las campanas de las iglesias, los aleteos y murmullos de las aves en las plazas, el susurro de las hojas de los árboles al viento en las avenidas y bulevares, el discurrir del agua por fuentes y 
surtidores, los músicos callejeros e incluso, el simple taconeo opaco producido por la circulación peatonal, contribuye a crear determinados ambientes perceptivos característicos de cada ciudad, no exentos de gracia. La percepción de estos sonidos urbanos en los espacios públicos es necesaria para conseguir un ambiente urbano de calidad:

En nuestras ciudades, si bien es verdad que aquellos que tienen a su cargo los aspectos estéticos trabajan para dar satisfacción a la vista, no es menos cierto que con frecuencia olvidan las tensiones a las que está sujeto el oído. Tanto los espacios sonoramente muertos como los saturados por el ruido no se aprecian (Bailly, 1979, p. 78).

La necesidad de dinamizar socialmente las periferias de las ciudades nos lleva a impulsar el desarrollo cultural urbano a través del mecanismo barrial. Un barrio está ligado a una zona de la ciudad con identidad propia, claramente percibida tanto por sus habitantes como por sus visitantes (Moreno González, 2013, p. 96). En la conformación de esa identidad, las componentes tanto sociales como estéticas juegan un importante papel. El urbanita posee una necesidad casi intuitiva de identificar la zona en la que vive: "La gente necesita pertenecer a una unidad espacial identificable [...]. Las personas desean ser capaces de identificar aquella parte de la ciudad en que viven, como algo distinto a todas las demás" (Alexander et al., 1980, p. 95). Por esto, la necesidad que tienen los espacios públicos situados en los barrios periféricos de conseguir identidad urbana - mejorando así su percepción social y estética- suele ser mayor que en los del centro de la ciudad, donde esa identidad ya forma parte del acervo cultural ciudadano y del sentimiento patrimonial que la sociedad percibe del mismo (Llull, 2005). La creación de espacios públicos en tejidos nuevos, donde la total ausencia de señas de identidad históricas ha conllevado una necesidad de "inventar el lugar" (Augé, 1993), ha llevado a los diseñadores a justificar sus actuaciones sobre esta premisa. Precisamente, en el acierto de esa invención del lugar y su correspondiente materialización, reside el baremo tanto de la calidad como de la correcta percepción social y estética de los espacios públicos urbanos o lo que es lo mismo, de la propia ciudad.

\section{Conclusiones}

La percepción social del espacio público es fundamental para su percepción estética. El espacio público no puede interpretarse en clave estética si previamente no lo ha sido en clave social, ya que ésta es la razón de ser de ese espacio. Sólo cuando la sociedad identifica y hace suyo el uso y función de un espacio público, comienza a preocuparse de su dimensión estética. Pero también es cierto lo contrario: la calidad estética de un fragmento urbano tan importante para la ciudad como es su espacio público, potencia su uso y por lo tanto mejora su percepción social. Esta iteración funciona siempre y cuando se produzca un deseable equilibrio entre ambas percepciones. Una percepción social alta pero estética baja, puede producir tensión ciudadana, que acabaría extendiéndose a la política. Por el contrario, una percepción 
social baja pero estética alta del espacio público, puede producir una suerte de pieza de museo casi ignorada.

La relación entre ambas percepciones del espacio público depende de tres variables: la planificación urbana, la arquitectura y el diseño del espacio público. La planificación proyecta trazados y crea tejidos urbanos mediante sistemas de ordenación urbana. Propone tipologías con sus correspondientes parámetros volumétricos y de posición que dan como resultado una determinada morfología urbana. Aunque abstracta e indirecta, es la primera impresión que el urbanita - quizá inconscientemente- percibe estéticamente. Por ello resulta diferente, por ejemplo, el paisaje urbano de un casco antiguo de trazado medieval, de un ensanche decimonónico o de una periferia del siglo XX, independientemente del lenguaje estético de sus arquitecturas y espacios públicos.

La arquitectura, mediante su cara visible desde el espacio público —-fachadastambién participa en la configuración del paisaje urbano. Una muestra de fachadas más o menos afortunadas, homogéneas o variadas tanto compositiva como estilísticamente, se percibe como el fondo del escenario público. Esta participación también queda patente en el nivel en el que los flujos e interacciones entre espacio público y privado son más evidentes: la cota cero o rasante de calle. Por esta razón resulta diferente, por ejemplo, un paisaje urbano de locales comerciales, de viviendas en planta baja o de simples vallados que separan radicalmente la frontera entre lo público y lo privado.

En tercer lugar, nos queda la configuración y diseño del espacio público mismo. Este aspecto es el que tiene una mayor inmediatez perceptiva en el observador urbano. Marca la primera impresión paisajística de la ciudad, no tanto por la repercusión general en la misma como por la cercanía y palpabilidad del paseante. En efecto, cuando llegamos por primera vez a una ciudad que no conocemos y pisamos el suelo - la perspectiva desde un vehículo en marcha es totalmente diferente- lo primero que percibe la vista suele ser el pavimento: adoquinado, asfalto, baldosa u hormigón. Después la presencia o no de arbolado y mobiliario urbano. Luego las señales y la publicidad comercial a cota cero, y finalmente, al levantar la vista, percibimos las fachadas arquitectónicas más inmediatas a nuestra posición.

El objetivo final de un espacio público - más allá de su función- es ser identificado como tal por sus usuarios, alcanzar carácter propio, conseguir hacerse acreedor de su aceptación ciudadana y parte intrínseca de la ciudad. El alcance de ese objetivo es el resultado de una compleja amalgama de variables sociales, históricas, políticas, económicas y culturales. Si además partimos de una adecuada percepción de la dimensión social y estética del mismo, facilitaremos su consecución y mejoraremos no sólo la calidad de los espacios públicos, sino de la ciudad en si misma.

\section{Referencias}

Alexander, C.; Ishikawa, S. \& Silverstein, M. (1980). Un lenguaje de patrones. Ciudades, Edificios, Construcción. Barcelona: Gustavo Gili.

Amendola, G. (2000): La ciudad postmoderna. Magia y miedo de la metrópolis contemporánea. Madrid: Celeste. 
Andreotti, L. \& Costa, X. (1996). Teoría de la deriva y otros escritos situacionistas sobre la ciudad. Barcelona: Actar.

Arnau, J. (2000). 72 Voces para un diccionario de arquitectura teórica. Madrid: Celeste.

Assunto, R. (1991). Ontología y teleología del jardín. Madrid: Tecnos.

Augé, M. (1993). Los No-Lugares. Espacios del anonimato. Una antropología de la sobremodernidad. Barcelona: Gedisa.

Aymonino, C. (1981). El significado de las ciudades. Madrid: H. Blume.

Ayús, M. (1996). La anticiudad. Legislación urbanística y la escena urbana como resultado político. Alicante: Naturaleza y derecho.

Bachelard, G. (1994). La poética del espacio. México D.F.: Fondo de Cultura Económica.

Bailly, A. (1979). La percepción del espacio urbano. Madrid: Instituto de Estudios de Administración Local.

Borja, J. (2003). La ciudad conquistada. Madrid: Alianza.

Borja, J. \& Muxí, Z. (2003). El espacio público. Ciudad y ciudadanía. Barcelona: Electa.

Cullen, G. (1974). El paisaje urbano. Tratado de estética urbanística. Barcelona: Blume.

De Gracia, F. (1992) Construir en lo construido. La arquitectura como modificación. Madrid: Nerea.

Favole, P. (1995). La plaza en la arquitectura contemporánea. Barcelona: Gustavo Gili.

Jameson, F. (1995). El posmodernismo o la lógica cultural del capitalismo avanzado. Barcelona: Paidós.

Kaika, M. \& Swyngedouw, E. (2000). Fetishizing the Modern City: The Phantasmagoria of Urban Technological Networks. International Journal of Urban and Regional Research, 24:1, 120-138.

doi: http://dx.doi.org/10.1111/1468-2427.00239

Koolhaas, R. (1996). Atlanta, en Bernadó, J. \& Prat, R. (eds). Atlanta. Barcelona: Actar.

Llull, J. (2005). Evolución del concepto y de la significación social del patrimonio cultural. Arte, Individuo y Sociedad, 17, 175-204.

Lyotard, J-F. (1999). La posmodernidad (explicada a los niños). Barcelona: Gedisa.

Marchán Fiz, S. (1986). Contaminaciones figurativas. Imágenes de la arquitectura y la ciudad como figuras de lo moderno. Madrid: Alianza.

Martínez Sarandeses, J. (2001). Diseño urbano para cualquier siglo, en Pecourt García, J. (dir.). Ciudad para la sociedad del siglo XXI (pp. 210-214). Valencia: Icaro.

Miranda, A. (1999). Ni Robot ni Bufón. Manual para la crítica de arquitectura. Madrid: Cátedra.

Moix, Ll. (1994). La ciudad de los arquitectos. Barcelona: Anagrama.

Montaner, J.M. (1993). Después del Movimiento Moderno. Arquitectura de la segunda mitad del siglo XX. Barcelona: Gustavo Gili. 
Moreno González, A. (2013). La cultura como agente de cambio social en el desarrollo comunitario. Arte, Individuo y Sociedad, 25(1), 95-110.

doi: http://dx.doi.org/10.5209/rev_ARIS.2013.v25.n1.41166

Németh, J. (2012). Controlling the Commons: How Public Is Public Space? Urban Affairs Review, 48, 811-835.

doi: http://dx.doi.org/10.1177/1078087412446445

Norberg-Schulz, C. (1975). Existencia, espacio y arquitectura. Barcelona: Blume.

Popelka, R. (2009). La posmodernidad y su reflejo en las artes plásticas. Arte Individuo y Sociedad, 21, 89-98.

Popper, K. (1982 [1934]). La lógica de la investigación científica. Madrid: Tecnos.

Rogers, R. \& Gumuchdjian, P. (2000). Ciudades para un pequeño planeta. Barcelona: Gustavo Gili.

Rossi, A. (1977). Para una arquitectura de tendencia. Barcelona: Gustavo Gili.

Ruiz Gómez, E.M. (2012). El jardín como elemento integrador del hombre en la metrópoli. Arte, Individuo y Sociedad, 24 (1), 147-157.

doi: http://dx.doi.org/10.5209/rev_ARIS.2012.v24.nl.38049

Sæter, O. (2011). The Body and the Eye: Perspectives, Technologies, and Practices of Urbanism. Space and Culture, 14(2), 183-196.

doi: http://dx.doi.org/10.1177/1206331210391137

Sequera, J. \& Janoschka, M. (2012). Ciudadanía y espacio público en la era de la globalización neoliberal. Arbor, vol. 188-755, 515-527.

doi: http://dx.doi.org/10.3989/arbor.2012.755n3005

Sitte, C. (1980 [1889]). Construcción de ciudades según principios artísticos. Barcelona: Gustavo Gili.

Turner, R. S. (2002). The Politics of Design and Development in the Postmodern Downtown. Journal of Urban Affairs, 24, 533-548.

doi: http://dx.doi.org/10.1111/1467-9906.00142

Verdú, V. (2001). La sociedad americana ¿sociedad del futuro?, en Pecourt García, J. (dir.). Ciudad para la sociedad del siglo XXI (pp. 81-97). Valencia: Icaro.

Von Buttlar, A. (1993). Jardines del Clasicismo y el Romanticismo, el jardín paisajista. Madrid: Nerea.

Zárate Martín, A. (1991). El espacio interior de la ciudad. Madrid: Síntesis. 